\title{
An Evaluation of Techniques Used to Index Recruitment Variation and Year-Class Strength
}

\author{
Michael C. Quist \\ Department of Natural Resource Ecology and Management, Iowa State University, \\ 339 Science II, Ames, Iowa 50011, USA
}

\begin{abstract}
Recruitment is one of the most important factors influencing fish population dynamics, and although long-term data are probably the best source of information for explaining recruitment dynamics, such data are often unavailable due to logistic or monetary constraints. Consequently, a number of indices have been developed to index recruitment variability and year-class strength from a single sample. The purpose of this study was to compare two indices, the recruitment variability index (RVI) and recruitment coefficient of determination (RCD), with empirical estimates of walleye Sander vitreus recruitment variability in eight Kansas reservoirs. In addition, Studentized residuals from catch curves were compared with empirical estimates of year-class strength. Empirical estimates of recruitment variability were not related to RCD or RVI values from a single sample, and Studentized residuals from catch curves did not adequately index walleye recruitment for any of the study populations. Sampling bias was probably not the cause for the observed patterns, but examination of age-specific mortality rates indicated that mortality differed among ages (e.g., the mortality of age- 2 fish was less than that of age- 3 and older fish) and that mortality of a given age differed through time (i.e., the mortality of age- 3 fish varied among years). These results suggest that angler behavior, in response to strong and weak year-classes, may affect the ability of indices to adequately assess recruitment dynamics. Mean RVI values estimated from multiple years of age structure data were significantly correlated with empirical estimates of walleye recruitment variability, suggesting that the RVI may be useful for indexing recruitment when data are available for more than 1 year. Although the indices examined in this study provide adequate assessments of recruitment dynamics for many fish populations, these results illustrate the importance of differential mortality among age-groups on index values and suggest that some form of index validation is necessary prior to their use.
\end{abstract}

Growth, mortality, and recruitment are the three primary factors (i.e., rate functions) influencing fish population dynamics (Ricker 1975). Although growth and mortality are critical factors regulating fish populations, recruitment is often viewed as the governing and most variable of the three rate functions (Ricker 1975; Gulland 1982). Recruitment variability contributes to uncertainty in fisheries management and may increase complexity associated with characterizing fish populations. For instance, recruitment variation can affect estimates of size structure (Gabelhouse 1984; Buynak and Mitchell 2002), growth (Gardiner and Shackley 1991; Pope et al. 2004), and mortality (Ricker 1975; Allen 1997), and may obscure population responses to management actions (Allen and Pine 2000; Buynak and Mitchell 2002). Consequently, understanding recruitment dynamics of fishes is critical for management and has been the focus of numerous studies (e.g., Larkin 1978; Miller et al. 1988; Frank and Leggett 1994). Most research on recruitment dynamics has focused on the influence of abiotic and biotic

\footnotetext{
* Corresponding author: mcquist@iastate.edu
}

Received March 29, 2006; accepted June 16, 2006 Published online February 1, 2007 processes on year-class strength (e.g., Hall and Rudstam 1999; Nunn et al. 2002; Coutant 2004). Understanding conditions related to year-class strength has obvious importance, but measures of recruitment variability (i.e., recruitment stability, absolute measures of variance) are also important for developing a comprehensive understanding of fish population dynamics. Recruitment variability of a species across different systems or periods in the same system may help identify spatial and temporal variation in environmental conditions (Guy and Willis 1995; Michaletz 1998; Pope and Willis 1998). For instance, Guy and Willis (1995) found that recruitment of black crappie Pomoxis nigromaculatus in South Dakota was more variable and missing year-classes were more common in natural lakes than in impoundments. Differences in recruitment among lake types were thought to be the result of wind action and the frequency of high-water levels. Moreover, recruitment stability was closely related to catch rates, growth, and condition of black crappie in the study systems. Thus, understanding recruitment variability and year-class strength provides important knowledge of factors influencing fish population structure and dynamics, which is necessary for making and evaluating management decisions. 
Assessing recruitment (i.e., year-class strength and variability) is probably best achieved using long-term data collected with standardized methods, but these data are often unavailable because of logistic or monetary constraints. In response to these limitations, a number of methods have been recently developed to index recruitment variability and year-class strength; these methods use age structure data obtained from one-time samples. Two methods have been proposed to index recruitment variability. The first method, the recruitment variability index (RVI), was developed by Guy and Willis (1995) and is estimated as follows:

$$
\mathrm{RVI}=\left[S_{N} /\left(N_{M}+N_{P}\right)\right]-\left(N_{M} / N_{P}\right),
$$

where $S_{N}$ is the sum of the cumulative relative frequencies across year-classes included in the sample, $N_{M}$ is the number of year-classes missing from the sample (year-classes beyond the oldest year-class in the sample are excluded), and $N_{P}$ is the number of yearclasses present in the sample $\left(N_{P}\right.$ must be greater than $N_{M}$ ). Recruitment variability index values vary from -1 to 1 , with values close to 1 representing stable recruitment. Development of the RVI was partially based on catch-curve analysis (i.e., linear regression of $\log _{e}$ [number of fish at age] on age) in that fish populations with stable recruitment will exhibit a steady decline in numbers with increasing age. The RVI was also developed by considering concepts traditionally used in community ecology, including measures of richness (e.g., number of present and missing yearclasses) and evenness (e.g., cumulative frequency distribution; Guy 1993; Guy and Willis 1995). As such, the RVI is sensitive to the occurrence of missing year-classes (Guy 1993; Guy and Willis 1995; Isermann et al. 2002). Because the RVI is based on a cumulative frequency distribution, weak or missing year-classes that occur at younger ages have a larger influence on RVI values than those occurring at older ages.

The other method, the recruitment coefficient of determination (RCD), was proposed by Isermann et al. (2002). The RCD is the coefficient of determination $\left(r^{2}\right)$ resulting from a catch curve (technically a catchcurve type regression). In populations exhibiting stable recruitment, age explains most of the variation in the number of fish at each age (i.e., through mortality) and results in high RCD values. Inconsistent recruitment is expected to result in less predictable trends in number at age and will result in low RCD values. Both the RVI and RCD assume that total mortality is equal among year-classes, and the RCD assumes that variation in the number of fish at each age not explained by age is solely a function of recruitment variation.

The RVI and RCD index recruitment variability, but managers are also commonly interested in identifying strong and weak year-classes. Maceina (1997) proposed using Studentized residuals from catch-curve regressions as an index of year-class strength (hereafter called the residual technique), where positive residuals represent strong year-classes and negative residuals represent weak year-classes. Similar to the RCD, a primary assumption of the residual technique is that variation in the catch curve is a function of recruitment, rather than differential mortality among year-classes. Since the initial proposal of the residual technique, a number of studies have used the method to evaluate recruitment dynamics (e.g., Slipke et al. 1998; DiCenzo and Duval 2002; Sammons et al. 2002; Maceina 2003).

The RVI, RCD, and residual technique are being used increasingly for describing recruitment variation and year-class strength, but only a few studies have compared and validated the indices. Maceina (1997) found that residuals indexed recruitment of largemouth bass Micropterus salmoides in two Alabama reservoirs. Also in Alabama reservoirs, Maceina and Stimpert (1998) showed that Studentized residuals adequately indexed year-class strength of crappies Pomoxis spp. Similarly, Studentized residuals were highly correlated with catch rates of age- 0 smallmouth bass Micropterus dolomieu in several Virginia rivers (Smith et al. 2005). When the RCD was proposed, Isermann et al. (2002) conducted a thorough evaluation of RVI, RCD, and the residual technique; they used a combination of simulation models and empirical data on 122 crappie populations from throughout North America. Results of the simulation models indicated that both RVI and RCD provided valid measures of recent recruitment variation. However, neither the RVI nor RCD was closely related to empirical measures of recruitment variation (i.e., coefficient of variation $[\mathrm{CV}=100 \times$ standard deviation/mean] in catch rates of age-1 fish) observed in long-term trap-net data. Similarly, Studentized residuals were related to empirical estimates of year-class strength for only 2 of 17 crappie populations (i.e., a subset of the 122 populations). In theory, the various measures of recruitment variation and yearclass strength should have indexed recruitment dynamics; however, gear biases associated with fall trap-net sampling were probably responsible for the lack of concordance between empirical measures and indices of recruitment dynamics (Isermann et al. 2002).

Obtaining long-term recruitment data is difficult, resulting in an increased reliance on indices for characterizing recruitment dynamics (e.g., Michaletz 1998; Slipke et al. 1998; Sammons et al. 2002). As such, additional evaluations on recruitment indices are needed to establish the conditions necessary for these indices to reflect recruitment variation and year-class strength. Thus, the purpose of this study was to 
evaluate whether RCD and RVI provided valid measures of recruitment variation and whether the residual technique adequately indexed year-class strength of walleyes Sander vitreus in Kansas reservoirs. Specifically, these techniques were compared with standardized sampling data collected from eight walleye populations.

\section{Methods}

Study area.-Walleyes were sampled during 1984 2004 from eight Kansas reservoirs: Cedar Bluff, Cheney, Glen Elder, Kirwin, Lovewell, Marion, Webster, and Wilson reservoirs. The study reservoirs have surface areas that vary from 1,327 to 5,093 ha (mean $\pm \mathrm{SD}, 2,649 \pm 1,410 \mathrm{ha}$ ), maximum depths that vary from 5.2 to $8.8 \mathrm{~m}(6.2 \pm 1.4 \mathrm{~m})$, and ratios of watershed area to lake area that vary from 8.1:1 to 1,079.0:1 (250.1:1 \pm 353.0:1). A number of studies have been conducted on walleye populations in the study reservoirs, the results of which have shown that walleye recruitment is related to a variety of abiotic and biotic conditions (Willis and Stephen 1987; Quist et al. 2003a), growth is relatively fast (e.g., Quist et al. $2003 \mathrm{~b}$ ), and total annual mortality $(A)$ is relatively high (41-61\% among reservoirs; Quist et al. 2004). All of the study reservoirs have important recreational walleye fisheries and are subject to either a 381-mm (Glen Elder, Kirwin, Webster, and Wilson reservoirs) or 457-mm (Cedar Bluff, Cheney, Lovewell, and Marion reservoirs) minimum length limit.

Walleye sampling and index calculations.-Walleye populations were sampled from each reservoir during fall (late October to early November) using gill-net complements. One gill net complement included four separate gill nets (each $30.5 \mathrm{~m}$ long $\times 1.8 \mathrm{~m}$ deep, with $2.5,3.8,6.4$, or $10.2-\mathrm{cm}$ bar mesh). Total length (mm) was measured from all fish, and hard structures for aging (i.e., scales and otoliths) were removed from five fish per 1-cm length-group. Years in which hard structures were collected varied from 2 to 7 years among reservoirs: Cedar Bluff (1992, 1993, 1996, 1996), Cheney (1995, 1996), Glen Elder (1991-1993, 1995, 1996, 1998, 1999), Kirwin (1996, 1998), Lovewell (1991-1993, 1995, 1996), Marion (1995, 1996, 1998), Webster $(1995,1996)$, and Wilson $(1995,1996)$ reservoirs. Scales were pressed onto 1.0-mm-thick acetate slides via a roller press and examined with a microfiche reader. Otoliths were used to corroborate scale age and to assign ages when difficulties with aging scales were encountered. Age structure of the walleye population for each reservoir and collection year (i.e., collection of hard structures) was estimated using an age-length key (Bettoli and Miranda 2001).

Recruitment was characterized as the catch per unit effort (CPUE, i.e., the number of fish per night per gill net complement) of age- 0 walleyes, which was plotted against the corresponding CPUE of other age-classes in each reservoir. For example, the CPUE of age- 0 walleyes sampled in 1990 was plotted against the CPUE of age-1 walleyes in 1991, the CPUE of age-2 walleyes in 1992, and so forth. Because hard structures were not collected during all sampling years, ages were assigned to walleyes using the most recent age-length key. The RVI was estimated from age structure information (as described by Guy and Willis 1995), and the RCD was estimated from weighted catch curves (Isermann et al. 2002). Estimates of RVI and RCD were obtained for each reservoir-year combination (i.e., only years in which hard structures were collected) and only included age-2 and older walleyes. Studentized residuals from the catch curve were used as an index of yearclass strength (as described by Maceina 1997).

Estimates of RCD and RVI were compared with the $\mathrm{CV}$ of the CPUE of age- 0 walleyes $\left(\mathrm{CV}_{\text {age- } 0}\right)$ to provide insight on how well the two indices reflected empirical estimates of recruitment variation. The $\mathrm{CV}_{\text {age-0 }}$ was only estimated for those years encompassed by the age structure data used to estimate RVI and RCD. For example, if walleyes were sampled in 1999 and the oldest year-class present in the sample was from 1993, the RVI and RCD estimated from the 1999 age structure data were compared with the $\mathrm{CV}_{\text {age- }}$ o estimated using catch rate data from 1993 to 1997 (i.e., only age- 2 and older fish were used). Estimates of $\mathrm{RVI}$ and RCD were plotted against the $\mathrm{CV}_{\text {age- } 0}$ for each reservoir-year combination, and weighted linear regression analysis was used to examine relations between RVI, RCD, and empirical estimates of recruitment variability. A weighted regression was used to reduce the influence of multiple years of data from any individual reservoir. Examination of individual reservoir-year combinations provided insight on what might be expected if one were to take a one-time sample. Because multiple years of age structure data are commonly available to managers, mean values of RVI and RCD were also examined. Mean RVI and RCD were estimated for each reservoir and compared with $\mathrm{CV}_{\text {age-0 }}$ via regression analysis. For these comparisons, $\mathrm{CV}_{\text {age-0 }}$ was estimated using catch rate data that spanned from the oldest year-class to the most recent sampling year in which hard structures were collected.

Studentized residuals from the catch curves were plotted against the associated CPUE of age- 0 walleyes. Similar to RVI and RCD estimates, regression analysis was used to examine relations between residual values and empirical estimates of year-class strength. Analyses (i.e., RVI, RCD, residuals) were conducted using 
untransformed CPUE data because the results obtained using $\log _{10}$ transformed data (i.e., $\log _{10}[\mathrm{CPUE}+1]$ ) were nearly identical to those obtained using untransformed data.

To better understand the effects of differential mortality among age-groups on recruitment indices, age-specific mortality rates were estimated for all reservoir-year combinations. Specifically, the frequency of fish of age $t$ (e.g., age 3) was divided by the frequency of fish of age $t-1$ (i.e., age 2 ) to provide an estimate of annual survival (Ricker 1975; Boxrucker 2002). This value was then subtracted from 1 and multiplied by 100 to provide an estimate of total annual mortality between age groups. Mortality was estimated for 1-year intervals beginning at age 2. All analyses were conducted using SAS (SAS 1996), and $\alpha=0.05$.

\section{Results}

Catch rates of age- 0 walleyes provided an excellent measure of recruitment to ages 1 and 2 but poorly indexed recruitment to ages 3 and 4 (Figures 1-4).
Age-0 walleye CPUE in a given year was highly correlated with CPUE of age-1 walleyes during the next year (Figure 1) and CPUE of age-2 walleyes 2 years later (Figure 2). However, catch rates of age-0 walleyes were not closely related to CPUE of age-3 (Figure 3) or age-4 (Figure 4) walleyes in any of the study reservoirs. The CPUE of age- 0 walleyes and corresponding catch rates of age- 5 and age- 6 fishes were not related for any of the populations.

Walleye recruitment, measured as the CPUE of age0 walleyes, was highly variable among and within reservoirs (Figure 5). Coefficients of variation associated with mean CPUE of age- 0 walleyes varied from 90 to 142 among reservoirs. Glen Elder and Marion reservoirs exhibited the lowest variation in walleye recruitment $\left(\mathrm{CV}_{\text {age-0 } 0}\right)$; Kirwin Reservoir had the highest variation in recruitment. Estimated RVI values varied from -0.004 to 0.95 and RCD values varied from 0.01 to 0.99 among reservoirs and years. Recruitment variability index values were significantly related to $\mathrm{CV}_{\text {age- } 0}$ but explained less than $35 \%$ of the

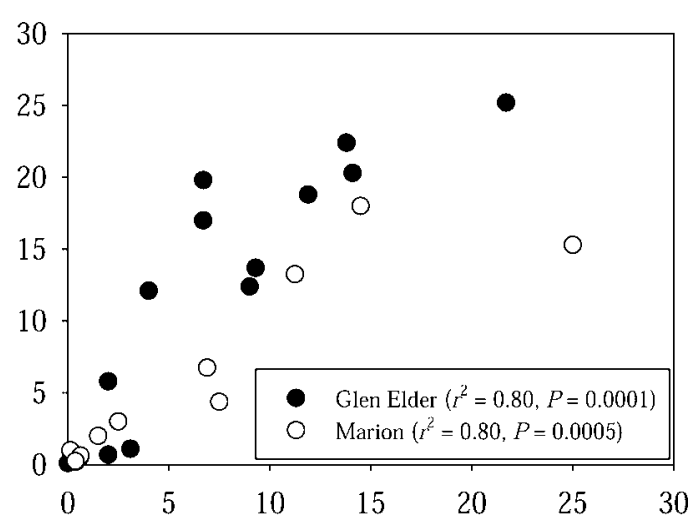

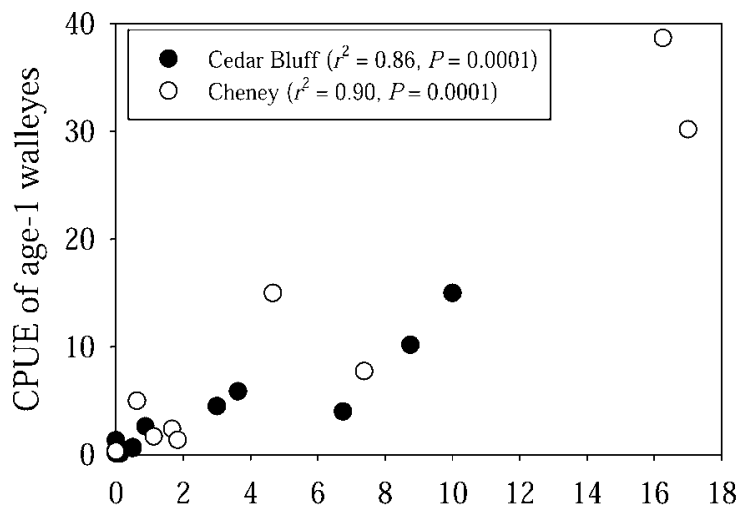

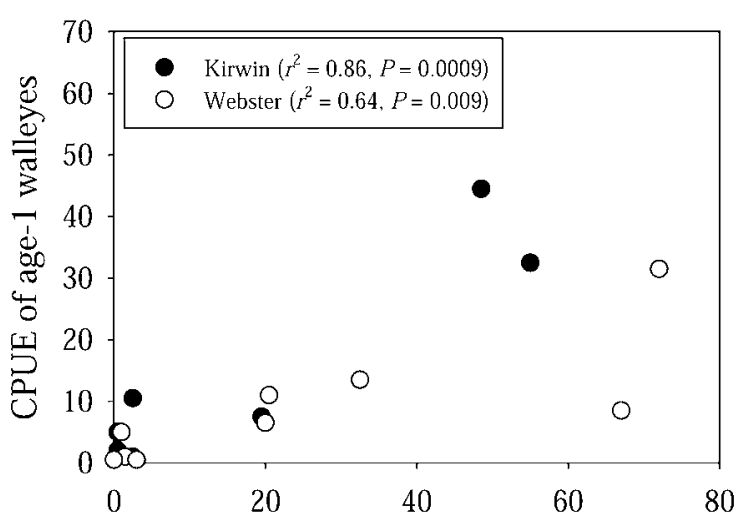

CPUE of age- 0 walleyes

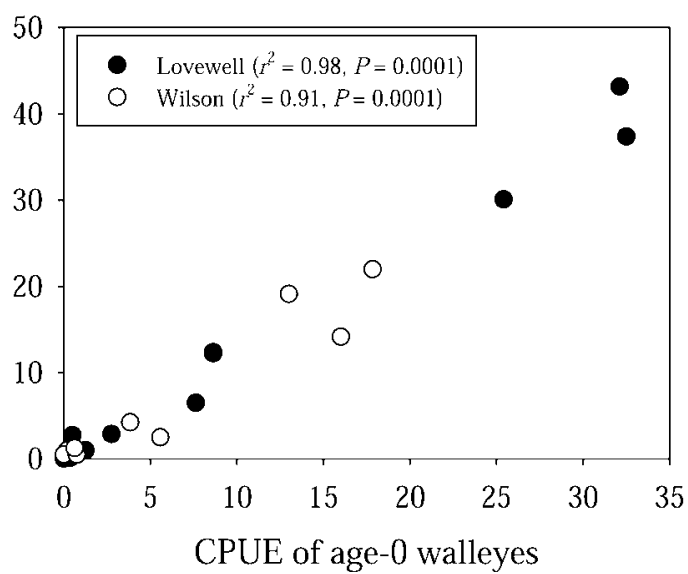

FIGURE 1.- Relationships between catch per unit effort (CPUE; number of fish per gill-net complement night) of age-0 walleyes at time $t$ and CPUE of age- 1 walleyes at time $t+1$ in eight Kansas reservoirs. 

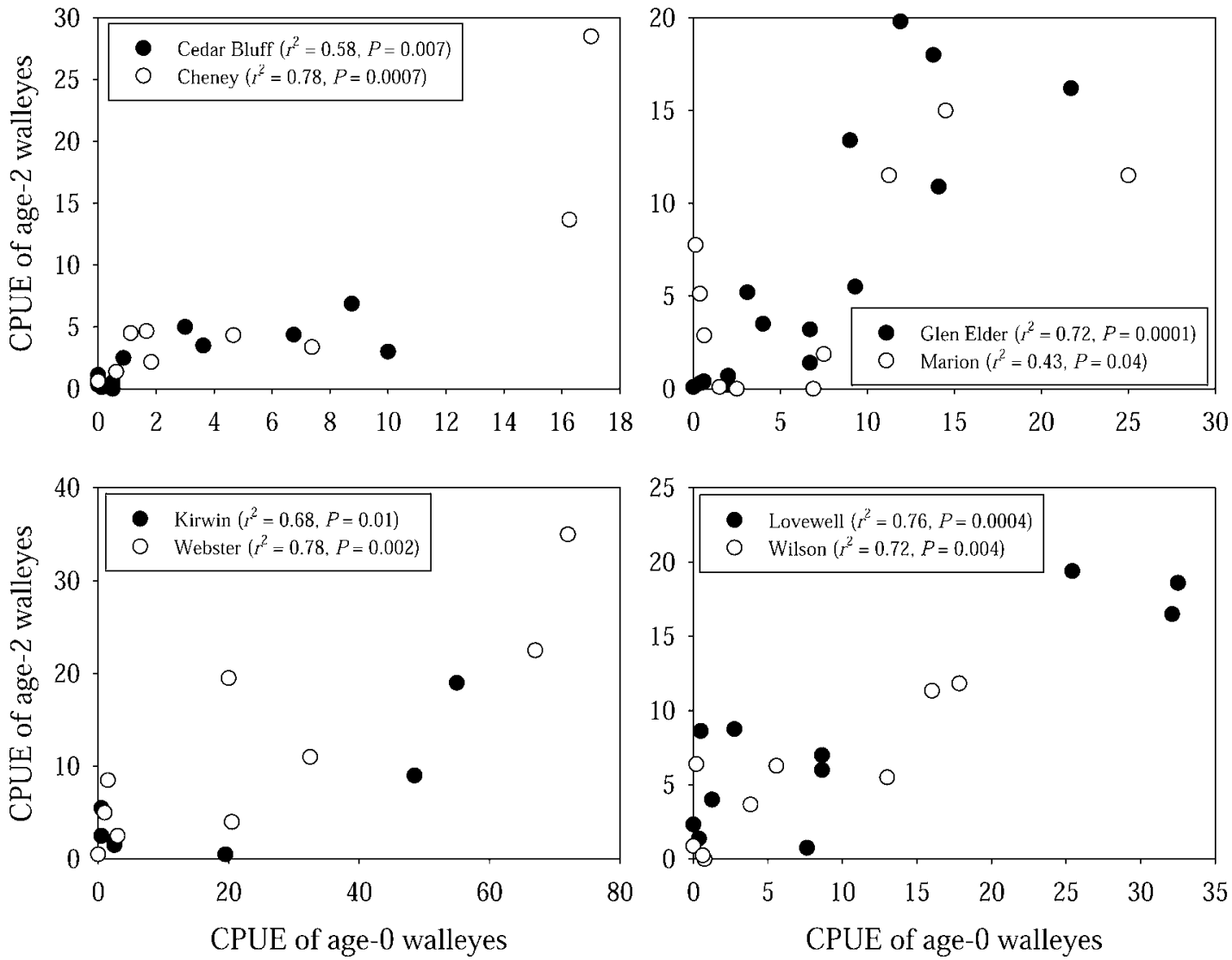

FIGURE 2.- Relationships between catch per unit effort of age- 0 walleyes at time $t$ and CPUE of age- 2 walleyes at time $t+2$ in eight Kansas reservoirs.

variation in empirical estimates of recruitment variation (Figure 6). Empirical estimates of walleye recruitment variability were not related to RCD values (Figure 6).

Mean RVI values were significantly related to $\mathrm{CV}_{\text {age-0 }}$ (Figure 7). Kirwin and Cheney reservoirs had the lowest mean RVI values and the highest $\mathrm{CV}_{\text {age- } 0}$; Glen Elder Reservoir exhibited the lowest empirical estimate of recruitment variation and the highest mean RVI value. Mean RCD values were not related to empirical estimates of recruitment variability (Figure 7).

Studentized residuals were not correlated with CPUE of age- 0 walleyes (Table 1 ). The only exception was for the sample collected in 1998 from Marion Reservoir, where Studentized residuals were significantly related to empirical estimates of walleye yearclass strength. Similar analyses were conducted by truncating catch curves to age- 3 and older walleyes and using unweighted catch curves, but the same results were obtained for all reservoirs and years.

The mortality of walleyes between age 2 and age 3 averaged $17 \%$ among reservoir-year combinations but was higher for older fish (Table 2). The variability among years also increased with age. For example, in Glen Elder Reservoir walleye mortality averaged $21.3 \%$ between ages 2 and 3, 50.8\% between ages 3 and 4 , and $51.8 \%$ between ages 4 and 5. In Lovewell Reservoir, mortality averaged $19.6 \%$ between ages 2 and 3,36.8\% between ages 3 and 4, and 34.8\% between ages 4 and 5. Similar results were observed for the other walleye populations. The $\mathrm{CV}$ of age-specific mortality increased with increasing age in all populations (Table 2).

\section{Discussion}

Variation in walleye recruitment was poorly indexed using RCD values, and year-class strength was not adequately indexed using residual values from catch curves. Recruitment variation was also poorly indexed using RVI values from a single sample, but mean RVI values provided an adequate index of recruitment variability. Several factors may help explain these 

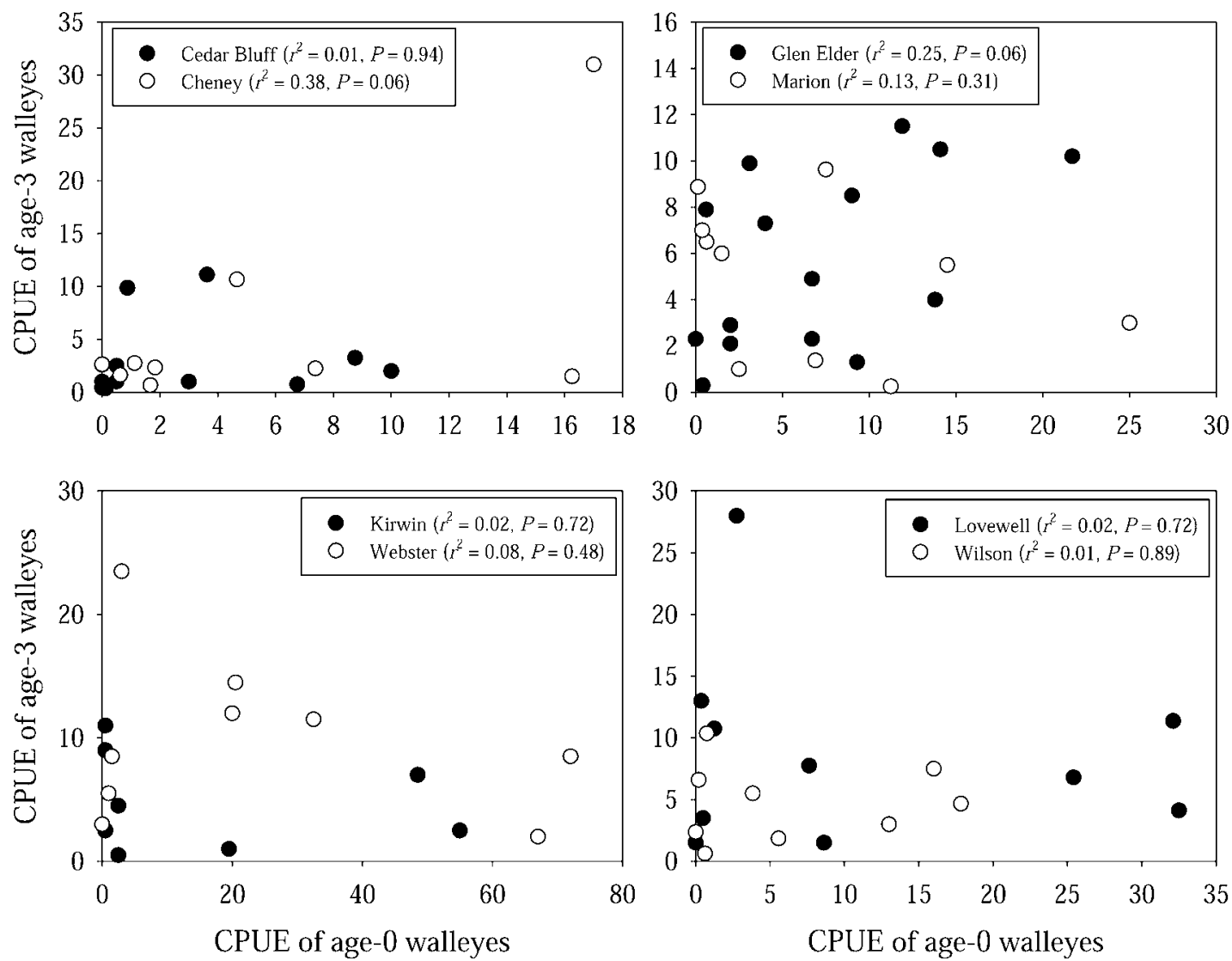

FIGURE 3.-Relationships between catch per unit effort of age- 0 walleyes at time $t$ and CPUE of age- 3 walleyes at time $t+3$ in eight Kansas reservoirs.

observations, including sampling bias and differential mortality among age-classes (Maceina 1997; Isermann et al. 2002). Issues associated with sampling include potential biases resulting from the time of year that fish were sampled or the sampling gear. If samples are biased towards specific age-groups (e.g., either young or old fish) because of differential habitat use or gear bias, then the corresponding age structure data and catch curves will also be biased (Ricker 1975; Maceina 1997). Although some sampling bias may be present in the data used for this study, sampling bias was probably minimal for fish older than age 2. For instance, Quist et al. (2002) sampled walleyes monthly from Glen Elder Reservoir using experimental gill nets and found results (i.e., size and age structure) from other seasons that were nearly identical to the data used in this study. Sampling with other gears (e.g., electrofishing, trap nets) has also yielded similar data (James Stephen, Kansas Department of Wildlife and Parks [KDWP], unpublished information). Fall gill netting is the standard season and gear for sampling walleyes in Kansas and many other systems in North America (e.g., Isbell and Rawson 1989; Fielder 1992; Stone and Lott 2002). As such, data used in this study reflect data that are being used by natural resource managers for describing walleye populations and making management decisions.

The other factor that may explain the observed results is differential mortality among age-groups. The techniques evaluated in this study assume that recruitment and mortality are the primary factors influencing the number of fish at each age and that mortality does not differ between ages (Maceina 1997; Isermann et al. 2002). Isermann et al. (2002) used simulation models to demonstrate that when mortality was consistent between ages and recruitment was varied, RCD and RVI adequately explained recruitment variation. In the current study, lack of concordance between RCD and the residual technique with empirical estimates of recruitment variation and yearclass strength was probably due to an increase in mortality of older fish resulting from recreational 

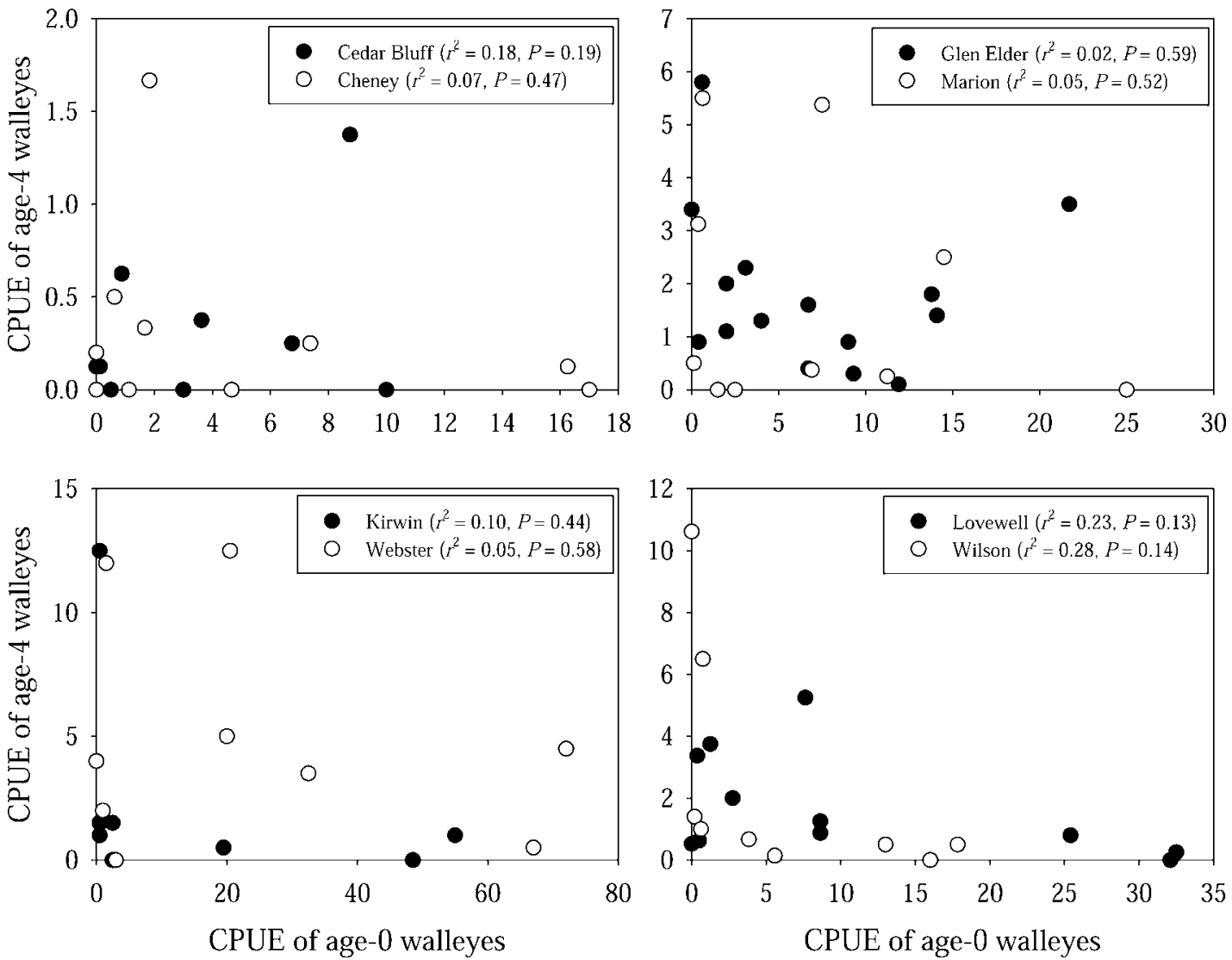

FIGURE 4.- Relationships between catch per unit effort of age- 0 walleyes at time $t$ and CPUE of age- 4 walleyes at time $t+4$ in eight Kansas reservoirs.

harvest. Total annual mortality of age- 2 and older walleyes is high $(40-60 \%)$ in the study reservoirs (Quist et al. 2004), and a recent study indicates that once fish reach a length where they are available for harvest (generally during their second or third growing season), $40 \%$ or more are harvested by anglers (James Stephen, unpublished information). These observations are consistent with age-specific mortality estimates presented in this study. Although different approaches may provide better estimates of age-specific total annual mortality rates (e.g., population density estimates through time), the method used in this study provides a general indication of differences in mortality among ages (Ricker 1975; Boxrucker 2002). Results of the age-specific mortality analysis indicated that mortality of walleyes increased around age 3 and remained relatively high at later ages. More importantly, mortality was not consistent among age intervals, and age-specific mortality rates varied among years. Specifically, the mean CVs of age-specific mortality estimates within reservoirs were generally less than
$20 \%$ for the interval from age 2 to age 3 but increased by $30-40 \%$ for older age intervals. This indicated that mortality varied among ages, mortality between ages 2 and 3 was relatively consistent, and mortality of older fish varied among years. Such a pattern may be responsible for the lack of relations between CPUE of age- 0 walleyes and CPUE of age- 3 and older walleyes and for failure of catch-curve-based indices to index recruitment dynamics in the study reservoirs.

Angling pressure varies greatly in Kansas reservoirs. For instance, creel surveys conducted by the Kansas Department of Wildlife and Parks showed that total angling effort on Cedar Bluff Reservoir averaged 1,276 $\mathrm{h} /$ month in 1997 versus 5,231 h/month in 1998, and on Glen Elder Reservoir anglers averaged 17,781 h/month in 1992 and 30,325 h/month in 1993 (Jason Goeckler, KDWP, unpublished information). Many recreational anglers are opportunistic in that they respond to changes in fish population abundance and catch rates. As catch rates of a given species decline in one area, effort is shifted to areas with higher catch rates. 

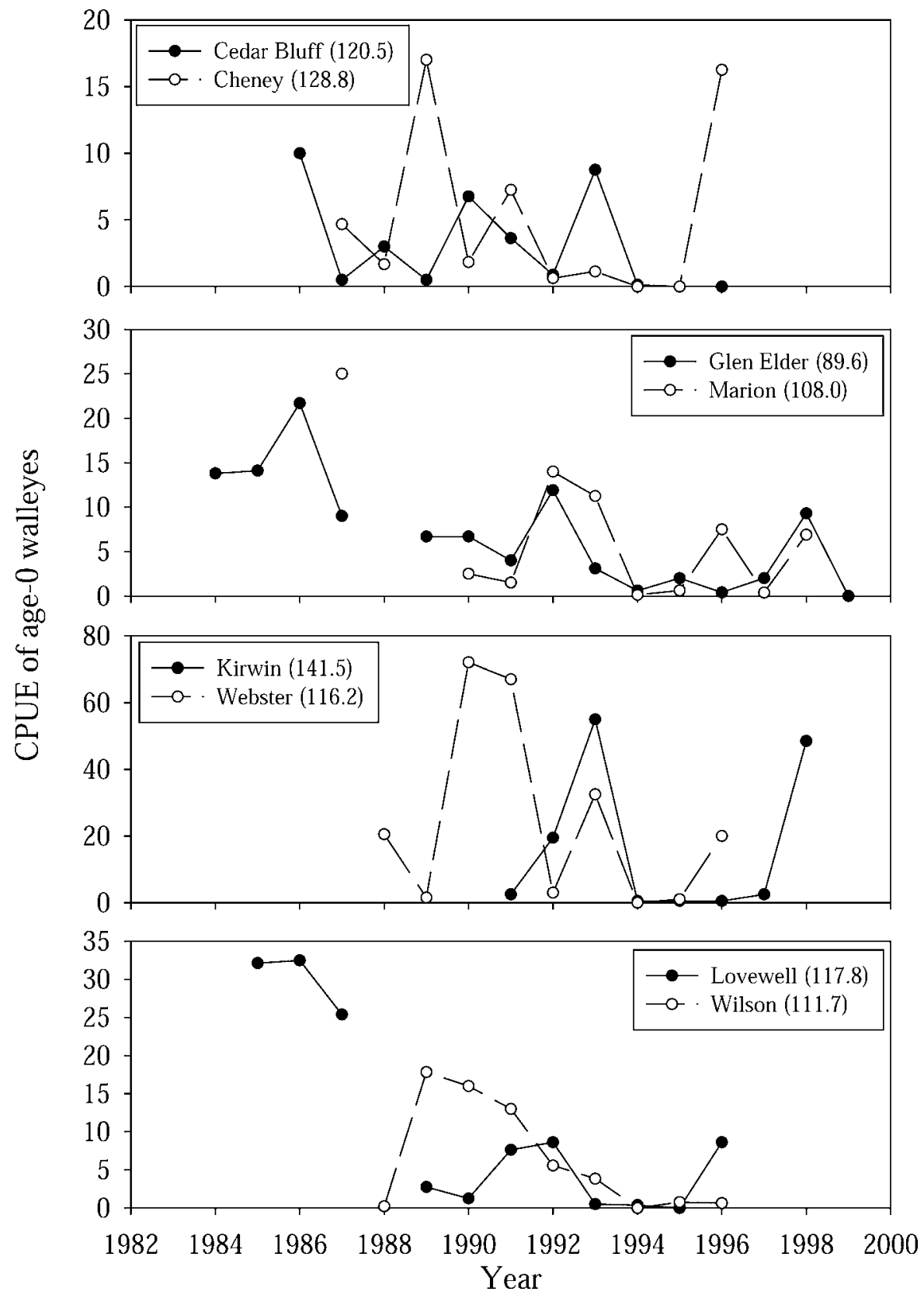

FIGURE 5.-Catch per unit effort of age-0 walleyes in eight Kansas reservoirs, 1982-2000. The numbers in parentheses are the coefficients of variation in CPUE.

Although this pattern is well-known in commercial fisheries (e.g., Larkin 1978), similar patterns have been observed in recreational fisheries, including walleye fisheries. For instance, Johnson and Carpenter (1994) examined patterns of walleye-angler behavior in Lake Mendota, Wisconsin, and found that as walleye population abundance and angler catch rates declined, there was a subsequent reduction in angling effort. One explanation for this pattern was that surrounding lakes offered alternative angling opportunities. A similar mechanism is thought to explain angler behavior in Escanaba Lake, Wisconsin, another well-studied walleye fishery (Carpenter et al. 1994). Although data are unavailable to determine the number of hours spent by 

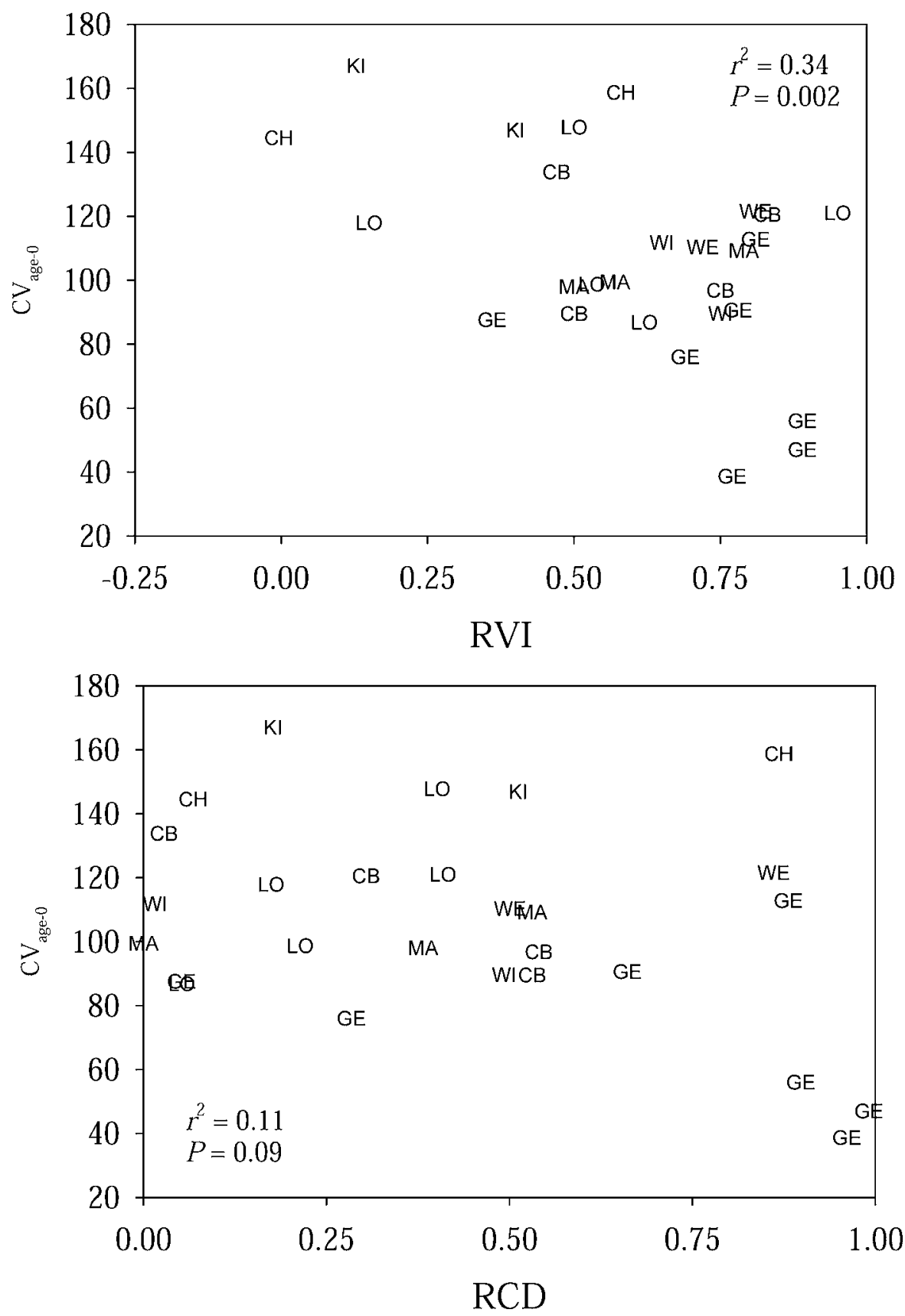

FIGURE 6.-Relationships between the coefficient of variation in catch per unit effort of age-0 walleyes and (1) recruitment variability index (RVI; top panel) and (2) recruitment coefficient of determination (RCD; bottom panel) values in eight Kansas reservoirs: Cedar Bluff (CB), Cheney (CH), Glen Elder (GE), Kirwin (KI), Lovewell (LO), Marion (MA), Webster (WE), and Wilson (WI) reservoirs. Individual data points are for the years in which hard structures were collected and age structure was estimated. 

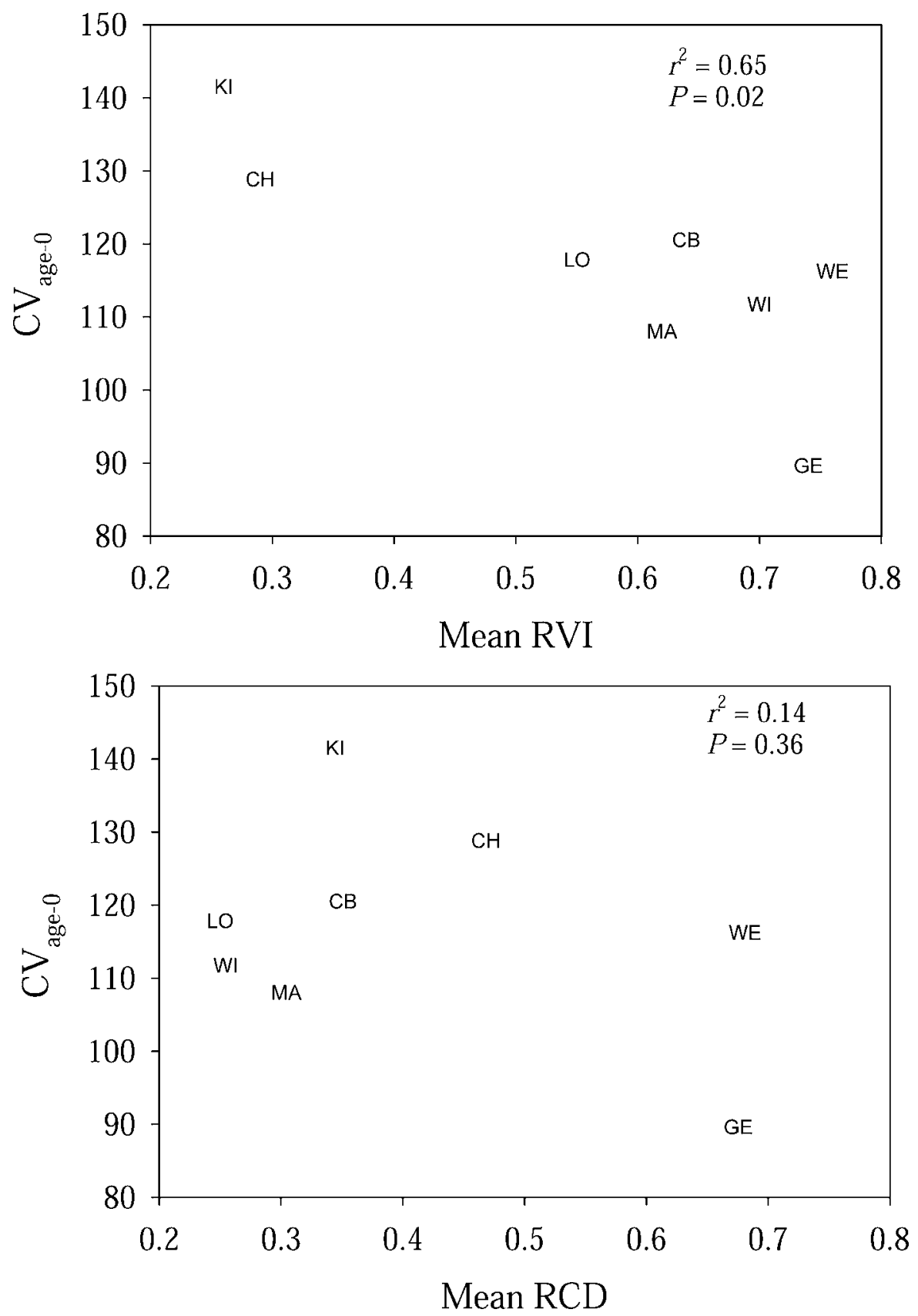

FIGURE 7.- Relationships between the coefficient of variation in catch per unit effort of age-0 walleyes and (1) mean recruitment variability index (RVI; top panel) and (2) mean recruitment coefficient of determination (RCD; bottom panel) values in eight Kansas reservoirs. The mean RVI and RCD values are averages across the years in which hard structures were collected and age structure was estimated. See Figure 6 for reservoir abbreviations.

anglers specifically targeting walleyes, angling pressure for walleyes in Kansas reservoirs appears to fluctuate with the presence and absence of strong yearclasses. When strong year-classes become available for harvest, managers often note that angling pressure is high compared with those years when the number of harvestable-length walleyes is low (James Stephen, KDWP, personal communication). As such, strong 
TABLE 1.-Relationships between Studentized residuals from catch curves (independent variable) and catch per unit effort of age-0 walleyes (dependent variable) in eight Kansas reservoirs. Catch curves were weighted and used age- 2 and older walleyes. The Pearson correlation coefficients $(r)$ and associated $P$-values are provided by reservoir and sampling year.

\begin{tabular}{|c|c|c|}
\hline $\begin{array}{l}\text { Reservoir and } \\
\text { sample year }\end{array}$ & $r$ & $P$ \\
\hline \multicolumn{3}{|l|}{ Cedar Bluff } \\
\hline 1992 & -0.64 & 0.36 \\
\hline 1993 & 0.19 & 0.70 \\
\hline 1995 & 0.63 & 0.26 \\
\hline 1996 & 0.74 & 0.09 \\
\hline \multicolumn{3}{|l|}{ Cheney } \\
\hline 1995 & -0.38 & 0.46 \\
\hline 1996 & -0.05 & 0.91 \\
\hline \multicolumn{3}{|l|}{ Glen Elder } \\
\hline 1991 & -0.16 & 0.79 \\
\hline 1992 & 0.91 & 0.28 \\
\hline 1993 & 0.38 & 0.62 \\
\hline 1995 & 0.43 & 0.46 \\
\hline 1996 & 0.46 & 0.36 \\
\hline 1998 & -0.15 & 0.76 \\
\hline 1999 & -0.14 & 0.77 \\
\hline \multicolumn{3}{|l|}{ Kirwin } \\
\hline 1996 & 0.15 & 0.82 \\
\hline 1998 & 0.45 & 0.54 \\
\hline \multicolumn{3}{|l|}{ Lovewell } \\
\hline 1991 & 0.22 & 0.78 \\
\hline 1992 & -0.54 & 0.46 \\
\hline 1993 & 0.19 & 0.80 \\
\hline 1995 & 0.17 & 0.75 \\
\hline 1996 & 0.65 & 0.16 \\
\hline \multicolumn{3}{|l|}{ Marion } \\
\hline 1995 & -0.01 & 0.98 \\
\hline 1996 & 0.51 & 0.38 \\
\hline 1998 & 0.84 & 0.02 \\
\hline \multicolumn{3}{|l|}{ Webster } \\
\hline 1995 & -0.08 & 0.88 \\
\hline 1996 & 0.54 & 0.34 \\
\hline \multicolumn{3}{|l|}{ Wilson } \\
\hline 1995 & 0.43 & 0.47 \\
\hline 1996 & 0.51 & 0.24 \\
\hline
\end{tabular}

year-classes probably receive increased angling pressure and harvest, whereas weak or moderate yearclasses experience reduced harvest. This pattern of angler behavior may explain the high variation observed in age-specific mortality rates. Consequently, recruitment indices based on catch curves may lack the sensitivity necessary to accurately reflect recruitment dynamics in these situations because recruitment peaks would probably be reduced and recruitment lows would be higher than might be expected.

Recruitment variability index values based on a single year of age structure data were significantly related to empirical estimates of recruitment variation, but the relationship was weak (i.e., $r^{2}=0.34$ ). In contrast, mean RVI values estimated from multiple years of age structure data explained $65 \%$ of the variation in walleye recruitment variability. Similar to
TABLE 2.- Mean total annual mortality (\%) between successive ages of walleyes from eight Kansas reservoirs. Means were estimated as the average mortality obtained from multiple sampling years (i.e., multiple estimates of age structure based on hard structures) within each reservoir. The numbers in parentheses are coefficients of variation (100 $\times \mathrm{SD} /$ mean). Mortality between successive ages was not estimable for several reservoirs and age intervals owing to the lack of fish of those ages or because the relative frequency of fish increased between ages (e.g., there were more age- 4 fish than age-3 fish).

\begin{tabular}{lcccc}
\hline & \multicolumn{4}{c}{ Age interval } \\
\cline { 2 - 5 } Reservoir & $2-3$ & $3-4$ & $4-5$ & $5-6$ \\
\hline Cedar Bluff & $15.0(6.7)$ & $31.8(84.4)$ & $41.0(69.6)$ & $\mathrm{a}$ \\
Cheney & $9.5(10.0)$ & $58.0(53.4)$ & $24.9(46.2)$ & $\mathrm{a}$ \\
Glen Elder & $21.3(19.0)$ & $50.8(49.0)$ & $51.8(59.6)$ & $18.5(26.3)$ \\
Kirwin & $\mathrm{a}$ & $0.75(0)$ & $\mathrm{a}$ & $\mathrm{a}$ \\
Lovewell & $19.6(5.3)$ & $36.8(45.9)$ & $34.8(28.6)$ & $30.3(40.0)$ \\
Marion & $27.0(29.6)$ & $32.0(40.6)$ & $45.7(80.4)$ & $47.3(38.3)$ \\
Webster & $14.5(6.7)$ & $58.5(27.1)$ & $42.5(74.4)$ & $\mathrm{a}$ \\
Wilson & $15.0(0)$ & $47.0(0)$ & $67.0(35.8)$ & $25.5(30.8)$ \\
\end{tabular}

${ }^{\text {a }}$ Not estimable.

RCD and the residual technique, RVI is based on age structure data; however, the index is unique in that it incorporates measures of year-class richness and evenness (Guy 1993; Guy and Willis 1995). When the index was proposed, Guy and Willis (1995) commented that RVI is sensitive to missing yearclasses. Not only were empirical estimates of recruitment variation relatively high for Kansas walleye populations, missing year-classes were common in the age structure data. For instance, we found that at least one year-class was missing in $41 \%$ of the reservoiryear combinations and as many as four in Cheney (1996 sampling year) and Lovewell (1996 sampling year) reservoirs. At least one year-class was missing in samples from Cheney and Kirwin reservoirs, the two populations with the highest $\mathrm{CV}_{\text {age- } 0}$ and lowest RVI values. Glen Elder, Marion, Webster, and Wilson reservoirs had the lowest $\mathrm{CV}_{\text {age-0}}$, the fewest number of missing year classes, and the lowest RVI values. Because the magnitude of differences between strong and weak year-classes was probably reduced by anglers focusing effort on stronger year-classes, the presence and frequency of missing year-classes may explain the ability of RVI to index recruitment variability, particularly if multiple years of age structure data are available.

Recruitment plays a critical role in regulating the population dynamics of fish, and there will continue to be a need for characterizing recruitment variation and year-class strength. I agree with Isermann et al. (2002) that standardized sampling over long periods will 
provide the best measures of recruitment dynamics. Unfortunately, such data are time-consuming and expensive to obtain, leading to the increased popularity of indices that can be calculated using one-time samples (e.g., Michaletz 1998; Pope and Willis 1998; DiCenzo and Duval 2002; Sammons et al. 2002). Although the indices examined in this study are useful for characterizing recruitment dynamics for many fish populations, issues associated with sampling bias (e.g., Isermann et al. 2002) or differential mortality among age-groups (this study) may result in poor performance of recruitment indices. Consequently, scientists should provide some measure of validation (e.g., Maceina 2003; Smith et al. 2005) whenever indices are used for evaluating recruitment variability or year-class strength.

\section{Acknowledgments}

I thank the numerous biologists and technicians that assisted in collecting information for this study, particularly K. Austin, T. Berger, C. Bever, S. Butler, L. Davignon, J. Delp, J. Goeckler, K. McClosky, S. Price, T. Mosher, G. Schneider, R. Schultz, and J. Stephen. I also thank C. Guy, M. Hawkins, D. Isermann, J. Larscheid, R. Schultz, J. Stephen, and D. Willis for valuable discussions associated with the study and D. Bauer, C. Guy, M. Hawkins, D. Isermann, J. Stephen, and two anonymous reviewers for their helpful comments on a previous version of the manuscript. Support for this project was provided by Iowa State University-Department of Natural Resource Ecology and Management.

\section{References}

Allen, M. S. 1997. Effects of variable recruitment on catchcurve analysis for crappie populations. North American Journal of Fisheries Management 17:202-205.

Allen, M. S., and W. E. Pine, III. 2000. Detecting fish population responses to a minimum length limit: effects of variable recruitment and duration of evaluation. North American Journal of Fisheries Management 20:672-682.

Bettoli, P. W., and L. E. Miranda. 2001. Cautionary note about estimating mean length at age with subsampled data. North American Journal of Fisheries Management 21:425-428.

Boxrucker, J. 2002. Rescinding a 254-mm minimum length limit on white crappies at Ft. Supply Reservoir, Oklahoma: the influence of variable recruitment, compensatory mortality, and angler dissatisfaction. North American Journal of Fisheries Management 22:13401348.

Buynak, G. L., and B. Mitchell. 2002. Response of smallmouth bass to regulatory and environmental changes in Elkhorn Creek, Kentucky. North American Journal of Fisheries Management 22:500-508.

Carpenter, S. R., A. Munoz-del-Rio, S. Newman, P. W. Rasmussen, and B. M. Johnson. 1994. Interactions of anglers and walleyes in Escanaba Lake, Wisconsin. Ecological Applications 4:822-832.

Coutant, C. C. 2004. A riparian habitat hypothesis for successful reproduction of white sturgeon. Reviews in Fisheries Science 12:23-73.

DiCenzo, V. J., and M. C. Duval. 2002. Importance of reservoir inflow to determine white bass year-class strength in three Virginia reservoirs. North American Journal of Fisheries Management 22:620-626.

Fielder, D. G. 1992. Relationship between walleye fingerling stocking density and recruitment in lower Lake Oahe, South Dakota. North American Journal of Fisheries Management 12:346-352.

Frank, K. T., and W. C. Leggett. 1994. Fisheries ecology in the context of ecological and evolutionary theory. Annual Review of Ecology and Systematics 25:401-422.

Gabelhouse, D. W., Jr. 1984. A length categorization system to assess fish stocks. North American Journal of Fisheries Management 4:273-285.

Gardiner, R., and P. Shackley. 1991. Stock and recruitment and inversely density-dependent growth of salmon, Salmo salar L., in a Scottish stream. Journal of Fish Biology 38:691-696.

Gulland, J. A. 1982. Why do fish numbers vary? Journal of Theoretical Biology 97:69-75.

Guy, C. S. 1993. Structure, dynamics, and movement patterns for crappies in South Dakota waters. Doctoral dissertation. South Dakota State University, Brookings.

Guy, C. S., and D. W. Willis. 1995. Population characteristics of black crappies in South Dakota waters: a case for ecosystem-specific management. North American Journal of Fisheries Management 15:754-765.

Hall, S. R., and L. G. Rudstam. 1999. Habitat use and recruitment: a comparison of long-term recruitment patterns among fish species in a shallow, eutrophic lake, Oneida Lake, NY, USA. Hydrobiologia 408/409:101113.

Isbell, G. L., and M. R. Rawson. 1989. Relations of gill-net catches of walleyes and angler catch rates in Ohio waters of western Lake Erie. North American Journal of Fisheries Management 9:41-46.

Isermann, D. A., W. L. McKibbin, and D. W. Willis. 2002. An analysis of methods for quantifying crappie recruitment variability. North American Journal of Fisheries Management 22:1124-1135.

Johnson, B. M., and S. R. Carpenter. 1994. Functional and numerical responses: a framework for fish-angler interactions? Ecological Applications 4:808-821.

Larkin, P. A. 1978. Fisheries management: an essay for ecologists. Annual Review of Ecology and Systematics 9:57-73.

Maceina, M. J. 1997. Simple application of using residuals from catch-curve regressions to assess year-class strength in fish. Fisheries Research 32:115-121.

Maceina, M. J. 2003. Verification of the influence of hydrologic factors on crappie recruitment in Alabama reservoirs. North American Journal of Fisheries Management 23:470-480.

Maceina, M. J., and M. R. Stimpert. 1998. Relations between reservoir hydrology and crappie recruitment in Alabama. North American Journal of Fisheries Management 18:104-113. 
Michaletz, P. H. 1998. Population characteristics of gizzard shad in Missouri reservoirs and their relation to reservoir productivity, mean depth, and sport fish growth. North American Journal of Fisheries Management 18:114-123.

Miller, T. J., L. B. Crowder, J. A. Rice, and E. A. Marschall. 1988. Larval size and recruitment mechanisms in fishes: toward a conceptual framework. Canadian Journal of Fisheries and Aquatic Sciences 45:1657-1670.

Nunn, A. D., I. G. Cowx, and J. P. Harvey. 2002. Recruitment patterns of six species of cyprinid fishes in the lower River Trent, England. Ecology of Freshwater Fish 11:74 84.

Pope, K. L., and D. W. Willis. 1998. Early life history and recruitment of black crappie (Pomoxis nigromaculatus) in two South Dakota waters. Ecology of Freshwater Fish 7:56-68.

Pope, K. L., G. R. Wilde, and B. W. Durham. 2004. Agespecific patterns in density-dependent growth of white crappie, Pomoxis annularis. Fisheries Management and Ecology 11:33-38.

Quist, M. C., C. S. Guy, R. J. Bernot, and J. L. Stephen. 2002. Seasonal variation in condition, growth, and food habits of walleye in a Great Plains reservoir and simulated effects of an altered thermal regime. Journal of Fish Biology 61:1329-1344.

Quist, M. C., C. S. Guy, and J. L. Stephen. 2003a. Recruitment dynamics of walleyes (Stizostedion vitreum) in Kansas reservoirs: generalities with natural systems and effects of a centrarchid predator. Canadian Journal of Fisheries and Aquatic Sciences 60:830-839.

Quist, M. C., C. S. Guy, R. D. Schultz, and J. L. Stephen. 2003b. Latitudinal comparisons of walleye growth in North America and factors influencing growth of walleyes in Kansas reservoirs. North American Journal of Fisheries Management 23:677-692.
Quist, M. C., J. L. Stephen, C. S. Guy, and R. D. Schultz. 2004. Age structure and mortality of walleyes in Kansas reservoirs: use of mortality caps to establish realistic management objectives. North American Journal of Fisheries Management 24:990-1002.

Ricker, W. E. 1975. Computation and interpretation of biological statistics of fish populations. Fisheries Research Board of Canada Bulletin 191.

Sammons, S. M., P. W. Bettoli, D. A. Isermann, and T. N. Churchill. 2002. Recruitment variation of crappies in response to hydrology of Tennessee reservoirs. North American Journal of Fisheries Management 22:13931398.

SAS (1996). SAS statistics user's guide. SAS Institute, Inc. Cary, North Carolina.

Slipke, J. W., M. J. Maceina, V. H. Travnichek, and K. C. Weathers. 1998. Effects of a 356-mm minimum length limit on the population characteristics and sport fishery of smallmouth bass in the Shoals Reach of the Tennessee River, Alabama. North American Journal of Fisheries Management 18:76-84.

Smith, S. M., J. S. Odenkirk, and S. J. Reeser. 2005. Smallmouth bass recruitment variability and its relation to stream discharge in three Virginia rivers. North American Journal of Fisheries Management 25:11121121.

Stone, C., and J. Lott. 2002. Use of a minimum length limit to manage walleyes in Lake Francis Case, South Dakota. North American Journal of Fisheries Management 22:975-984.

Willis, D. W., and J. L. Stephen. 1987. Relationships between storage ratio and population density, natural recruitment, and stocking success of walleye in Kansas reservoirs. North American Journal of Fisheries Management 7:279-282. 